\title{
Extrait du registre provisoire des actes de naissance constatés pendant l'année 1792 :
}

\author{
(2) OpenEdition \\ 1 Journals \\ Édition électronique \\ URL : https://journals.openedition.org/ahrf/1845 \\ DOI : 10.4000/ahrf.1845 \\ ISSN : 1952-403X \\ Éditeur : \\ Armand Colin, Société des études robespierristes
}

Édition imprimée

Date de publication : 1 décembre 2000

Pagination : 134

ISSN : 0003-4436

\section{Référence électronique}

«Extrait du registre provisoire des actes de naissance constatés pendant l'année 1792 : », Annales historiques de la Révolution française [En ligne], 322 I octobre-décembre 2000, mis en ligne le 22 mars 2006, consulté le 24 avril 2022. URL : http://journals.openedition.org/ahrf/1845; DOI : https://doi.org/ 10.4000/ahrf.1845

Ce document a été généré automatiquement le 24 avril 2022.

Tous droits réservés 


\section{Extrait du registre provisoire des actes de naissance constatés pendant l'année 1792 :}

1 «Ce jourd'hui 8 juillet 1792, l'an 4e de la liberté, est comparu par devant nous officier municipal administrateur de police étant actuellement à la maison commune, dans le lieu des séances ordinaires du corps municipal, les portes demeurant ouvertes Lucie Simplice Camille Benoît Desmoulins, citoyen, membre du Conseil général de cette commune, demeurant à Paris, rue du Théâtre Français ;

2 Lequel nous a dit que le 6 de ce mois, 9 heures du matin, il lui est né un fils du légitime mariage de lui comparant avec Anne Lucile Philippe Larison Duplessis ;

3 Que la liberté des cultes étant décrétée par la Constitution, et que par un décret de l'assemblée nationale législative, relatif au mode de constater l'état civil des citoyens, autrement que par des cérémonies religieuses, il doit être élevé dans chaque municipalité chef-lieu un autel sur lequel les pères assistés de deux témoins présenteront à la Patrie leurs enfants, le comparant voulant user des dispositions de la loi constitutionnelle, et voulant s'épargner un jour de la part de son fils le reproche de l'avoir lié par serment à des opinions religieuses qui ne pourraient pas encore être les siennes et de l'avoir fait débuter dans le monde par un choix inconséquent entre les neuf cents et tant de religions qui se partagent les hommes, dans un tems où il ne pourrait pas seulement distinguer sa mère ;

4 En conséquence il nous requiert pour constater la naissance et l'état civil de son fils, qu'il nous a fait présenter sur le bureau en présence de Laurent Lecointre et d'Antoine Merlin, citoyens députés à l'Assemblée nationale, de recevoir sa présente déclaration voulant que son fils se nomme Horace Camille Desmoulins, de laquelle déclaration il requiert qu'il en soit fait transcription dans le registre qui sera ouvert conformément à la loi cy-dessus rappelée, et que la présente minute soit par nous en attendant déposée au greffe de la municipalité et dont expédition lui sera donnée, ainsi signée par lui déclarant avec nous et les témoins cy-désignés, les jours et an que dessus.

5 Signé : Camille Desmoulins, MERLIN, député, 
6 L. LECOINTRE, député,

7 et SERGENT, administrateur de police. »

\section{BIBLIOGRAPHIE}

Archives départementales de Paris, V8E/18, Collection Hermès, Lettres C-D : Desmoulins. 